\title{
Research on Risk Propensity and Decision-making Satisfaction of Narcissistic Customer Investment Products based on Network Platform Questionnaire
}

\author{
Shuliang $\mathrm{Lv}^{1,2}$, Tiange Duan ${ }^{1}$ and Lanying $\mathrm{Du}^{1, *}$ \\ ${ }^{1}$ School of Management, Huazhong University of Science and Technology, Wuhan \\ 430074, China \\ ${ }^{2}$ Zhengzhou Branch China CITIC Bank, Zhengzhou 450001, China \\ lshul@126.com,*lanyingdu@163.com
}

\begin{abstract}
This study explores the differences of narcissistic customer financial investment in the bank's risk propensity and decision-making satisfaction. Studies have shown that overt narcissism customers have the higher degree of risk propensity. Investment professionals in overt narcissism and risk propensity between positive regulation effect is obvious, and overt narcissism and the degree of satisfaction with decision making is related; covert narcissism customer and risk propensity and decision-making satisfaction relationship is not significant and investment professionals in covert narcissism and risk propensity among regulatory role is not obvious. Covert narcissism and overt narcissism tendency and differences in risk decision satisfaction provide new ideas for the design and marketing of financial products.
\end{abstract}

Keywords: Narcissism, Investment professionals, Risk preference, Decision satisfaction

\section{Introduction}

Narcissism, is a personal love yourself, love yourself, but the deeper than self love and self-esteem. Dewall (2011) will be interpreted as a narcissistic expansion and grandiose self perception [1]. Sedikides (2007) found that narcissistic personality people tend to have self centered, self expansion, dominant and manipulative features such as [2]. Since the beginning of the 1970s, western countries seem to enter the self center in, the social atmosphere tend to the pursuit of personal value and the realization of individual happiness, so it is called "self era" me generation), also known as the "narcissism" of the era. With the rapid development of the Internet, self and microblogging control as the representative of narcissism in China also quickly became popular. Fukunishi (1996) according to three university research actually shows Chinese the highest level of narcissism; it seems that narcissism has developed into a global phenomenon [3].

Narcissism in the psychological and sociological aspects of the research results are more concentrated, but the application in commercial marketing subject is less and less. Dunning (2007) and Sedikides (2007) through the study found that narcissistic customer in product information and product purchase process performance with them on their own judgment consistent. They prefer products scarce, symbolic characteristic, and it is easy to ignore product utility properties [4]. This discovery provides very useful clues for business development and marketing of products, but the problem of narcissism for investment type financial products customer preference is not involved. At the same time, the existing research is to buy analysis before making decisions, for the customer satisfaction of narcissism, no answer. Thus, we try to expand the scope of research, to explore the narcissistic customer in the purchase of financial products have no obvious 
tendency of risk? Customer satisfaction and narcissistic investment for the general customers have no difference? In addition to the narcissistic factors of customer itself, whether there are other variables that can influence the investment risk propensity to affect investment decisions? Empirical study found that overt narcissism, the higher the degree of the customer have the stronger risk propensity, investment professionals in overt narcissism and risk propensity between positive regulation effect is obvious, and overt narcissism and the degree of satisfaction with decision making is related; covert narcissism customer and risk propensity and decision-making satisfaction is not significant and investment professionals in covert narcissism and risk propensity among regulatory role is not obvious.

Study on this problem both for the complement and deepening the theory of narcissism or for the practice of marketing of financial products has important significance. The first theory, this study will first connect with the concept of narcissism tendency and risk decision satisfaction, and the introduction of investment professionals to measure the risk of narcissism and tendency of positive reinforcement. In addition, the conclusion of this study complements and enriches the research field of narcissism, but also provides a new perspective for the study. Practice and along with the gradual maturity of the market economy and the development of the financial industry, more and more people began to get involved in financial products investment, through the understanding of narcissistic customer for financial products investment risk propensity, help to financial institutions to correct assessment of their investment preferences, thus the needle on the design and marketing of financial products, to meet the needs of customers. The following pages will be the first to carry out literature review, model and hypotheses are put forward according to the related theory and by way of experimental design to collect data and analysis and hypothesis testing, thus draws the conclusion of the study, finally discusses the significance of research results, limits and future research directions.

\section{The Theoretical Background and Hypothesis}

\subsection{Narcissism}

Freud in 1914, the earliest of narcissism in the specific definition, he believes that narcissism is a baby in early childhood except outside themselves for the reality of the unconscious phenomenon, later narcissism gradually by scholars as a pathological personality, the main symptoms as arrogant hold with an obsessive ambition and arrogance, and in interpersonal violent irritability. Lee (2013) through the study of narcissism redefine a normal personality traits, mainly consists of three components, namely exaggerated the positive self-concept, maintain the positive self concept of the self adjusting strategy and low empathy, low Pro density relationships [5-6]. Wink (1991) found that narcissism is composed of two independent types, their common point is only to get compliments in order to obtain satisfaction [7], and the two types are overt and covert narcissism.

Overt narcissism will directly show an exaggerated sense of, there are obvious desire and self expansion, in particular, bent on obtaining the envy of others [8]. Therefore, the dominant narcissists are also known as "forgetful (oblivious) narcissist" [8]. On the contrary, covert narcissism more performance for an introvert behavior, their surface is shy and depression, but the heart is very eager to be recognized, habits by their feedback to management self-esteem [9]. In fact, this more is a low self-esteem [11]. Therefore, the recessive narcissists are also often called "allergy (hypersensitive) narcissist" [10]. 


\subsection{Narcissism, Professional Degree and Risk Tend to Customers}

Those narcissists have a stronger tendency of many risk research. Lakey (2007) study found that narcissism and pathological gambling symptoms showed a positive correlation, and gambling frequency and the gambling stake number showed positive correlation [12]. Compared with non narcissists, narcissistic decision is subject to short-term incentive guide, narcissists in the decision whether to participate in risky behavior, focusing on the potential rewards and ignore the potential risks. Foster (2003) study shows that narcissists tend to a higher risk of stock investment and this phenomenon and not because of gender change [13-14]. Narcissistic customer for overt narcissism customer and covert narcissism customer, overt narcissism customer more open and self expansion, bent to the envy of others, driven by the superiority and a sense of entitlement traits, are more likely to make risky business for good results; covert narcissism customer is more shy and depression, especially need someone recognized, it is difficult to bear the bad consequences. Besides the characteristics of narcissistic personality itself will affect the investment risk tendency, there are other factors? The study found that customer professional degree will influence the information search and information processing, customer involvement, perceived price accuracy [15]. In the process of investment and financial management products, the professional degree of the customer will to their more confidence, through the information search, information processing ability and the impact of investment risk propensity, more willing to make bold investment decisions. In view of this we propose a hypothesis:

Hypothesis 1: customer risk the higher the tendency of the higher degree of overt narcissism.

Hypothesis 2: the higher risk customers tend to lower the degree of covert narcissism.

Hypothesis 3: the higher the degree of professional customers in the case, enhancement of risk propensity of overt narcissism.

Hypothesis 4: the higher the degree of professional customers in the case, enhancement of risk propensity of covert narcissism.

\subsection{Narcissism and Decision Satisfaction}

The relationship between narcissism and satisfaction of investment decision is reflected in two aspects. First of all, the customer due to excessive self-esteem of their own narcissism and self expansion, they decided to have a good sense of self demand higher. Risk decision is not only a kind of pure "computing" activities around the probability of profit and loss and expansion, also involves the deep desire and motivation. People maintain self-esteem and good feelings of self demand caused by the various decision satisfaction deviation. In order to maintain the balance of narcissistic customer cognitive itself will try to recognize their own investment decisions, although some investment proved to be unwise. Secondly, as shown in the previous research conclusion, narcissistic customers have more obvious tendency of risk, that risk is worth, they can accept the risk brought huge gains may also cause huge losses to the fact. Therefore, based on the good psychological adjustment, they to to less anxiety and can forgive investment failure, thus higher investment satisfaction. Covert narcissism customer risk tendency is weak, so the consequence of risk acceptance is low, so the investment satisfaction is relatively low. Based on this, we propose a hypothesis:

Hypothesis 5: the higher the risk propensity, customer satisfaction is high decision.

Hypothesis 6: risk tendency plays a mediating role between overt narcissism and decision satisfaction. 
Hypothesis 7: risk tendency plays a mediating role between covert narcissism and decision satisfaction.

\subsection{Conceptual Model}

The relationship between narcissism and mode of professional degree, risk propensity and customer satisfaction based on decision making, this study proposes an integrated conceptual framework. Customer risk the higher the tendency of overt narcissism degree is higher; the higher risk customers tend to lower the degree of covert narcissism. In the customer professional degree more high, enhancement of overt narcissism risk propensity. The higher the risk propensity, customer satisfaction is high decision. Risk propensity plays a mediating role between overt narcissism and decision satisfaction. Risk propensity plays a mediating role between covert narcissism and decision satisfaction, the concept of concrete framework as shown in Fig. 1.

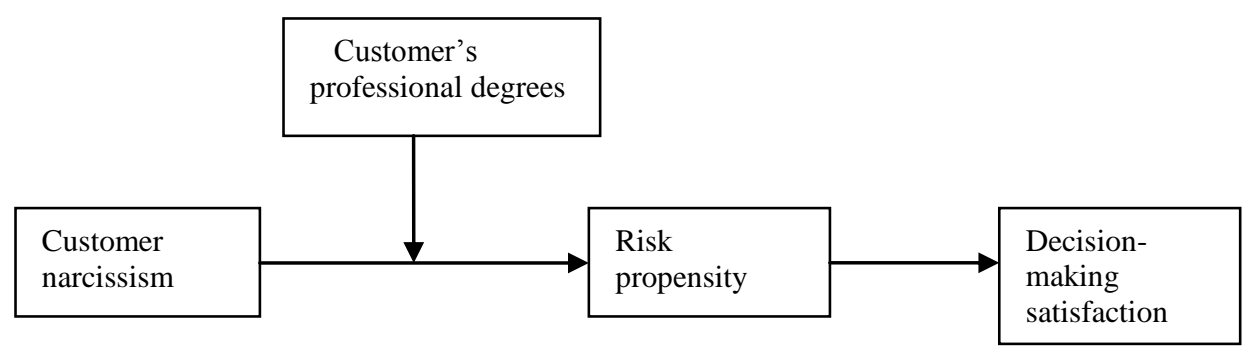

Figure 1. The Research Framework

\section{Data Analysis and Discussion}

\subsection{Sample Selection and Sample Characteristics}

Through an online questionnaire (Sojump online questionnaire) way to collect data, background research for financial products, and the study chose a bank's financial products Zhengzhou customers. In order to encourage participation of the subjects, and the subjects to fill out the questionnaire provided us with a small gift as a reward. Financial products as customers chose to study because this study wants to understand the risks narcissistic tendencies and customer satisfaction issues decisions when investing in financial products, the bank's customers are financial products that best meet our study sample, there will be no fill in the questionnaire do not understand the process and other issues.

In this study, the survey method 289 questionnaires were recovered; the analysis excluded incomplete questionnaires answered 16 parts. Sex ratio questionnaire respondents are: women accounted for $39.6 \%$, men accounted for $60.4 \%$; the age structure: $24.7 \% 30$ years of age, $30-50$ years old accounted for $61.3 \%$, $14 \%$ over 50 years; educational structure is: accounting for $46.7 \%$ of college, 23.7 percent of college and the rest accounted for $29.6 \%$; monthly family income structure (unit: $\mathrm{RMB}$ ) is: $2000-5000$ accounted for $25.4 \%$, 5000-10000 accounting for $39.1 \%$, $10000-30000$ accounted for $30.2 \%$, remaining $5.3 \%$.

\subsection{Variable Measurement}

The original scale study used the questionnaire in the translation, using two-way translation technology to ensure the quality of translation statement. And formally issued in the questionnaire before in a small range of pre filled test, let the 
experimenter assessment statement whether vague or difficult to understand, and adjust the feedback, and then release a large number of. The four variables involved in this study are based on the classical Li Kete five scales.

Measurements on narcissism, currently popular in foreign countries is used since the lover lattice volume table (NPI) measurement of overt narcissism, Minnesota Multiphasic Personality table (MMPI) measuring covert narcissism. But the two scales are based on the background of western development, not applicable to our sample. Chinese scholar developed a sample of our country the narcissistic personality inventory table, the table contains a total of 28 items, which 20 overt narcissism topic, 15 hidden a narcissistic, overt and covert narcissism have seven common topic. Including "I want to be a leader, I often feel useless, I love watching myself in the mirror and other items. In this paper, we use the learn huangmin (2014) to measure customer investment professional degree four items, including "for fund related products and services, I have more experience", "for financial products and services, I have rich knowledge", "for the employees of some financial advice and recommendation, I usually can't well understand", "I know and understand their purchase of financial products and services". The third question is reverse problem.

The measurement of attitudes to risk, this paper uses Pennings (2002) a psychological scale reveals consumer risk propensity [16] design. The advantages of revealing risk tendency through the scale method were easy to answer questions, can effectively reflect the actual decision content of specific products. Based on the research contents of this paper will questionnaire with minor changes, specifically the three items, including "for me, the investment is worth the risk of", "I can't accept the investment risk", "investment may be inconsistent with expectations, I am willing to accept the risks of failure of the investment". The third question is reverse problem.

The measurement on decision satisfaction, we used Fitzsimons (2000) experimental items of [17], but in order to fill the scale by ten to five. A total of six items, including "I think financial products selection frustrating", "to choose good many financial products", "I think the selection process is very good", "if the next purchase, I hope anymore. A kind of choice", "I believe that choose to buy the financial products of the process is very interesting", on my own in the selection process of experience very satisfied. The first question is the reverse problem.

\section{Empirical Analysis}

\subsection{Analysis of the Reliability and Validity}

This study used confirmatory factor analysis (CFA) to measure the model structure relates to the validity of letter variables. Table 1, table 2 and table 3 for specific items and the factor loadings, which overt narcissism in 13, 14 and 20 questions, covert narcissism in 28, 29 and 35 questions, factor loading less than 0.5 , so in the following analysis we will delete it. Each scale factor loads based on the confirmatory factor model to calculate the composite reliability (CR) in more than 0.74 , than the proposed critical values of 0.7 ; average variance extracted above 0.661 , have reached the recommended by the critical value of 0.5 requirements [18-19]. This shows that the measurement model of this study has good convergent validity.

In addition, we also examined the validity of the measurement, measuring whether there is confusion between the variables. As shown in Table 4, measured in this study, the average variance extracted five latent variables (AVE) than it is related to other variables between the coefficients of the square, which shows good discriminant validity of variable measurement. 
Table 1. Overt Narcissism Measurement

\begin{tabular}{|l|c|}
\hline \multicolumn{1}{|c|}{ Item } & Load factor \\
\hline 1.I want to be a leader & .847 \\
\hline 2. I think I will become a good leader & .840 \\
\hline 3.I love this role as decision makers & .854 \\
\hline 4. the power has a strong attraction for me & .671 \\
\hline 5. I was born to be a leader & .789 \\
\hline 6.I believe that they will become a great man & .724 \\
\hline 7.everyone love to listen to my story & .596 \\
\hline 8.I can easily make people believe everything I said & .690 \\
\hline 9. I have the talent to influence others & .679 \\
\hline 10.I did not go out of their way to attract the attention of others & .579 \\
\hline 11.I know that I am the best, because everyone says so. & .662 \\
\hline 12.people can learn many things from me & .576 \\
\hline 13. I envy other people's good luck & $\mathbf{. 0 5 4}$ \\
\hline 14. I expect a lot from others & $\mathbf{. 2 3 0}$ \\
\hline 15. if people do not pay attention to me, I will feel flat & .618 \\
\hline 16.unless I get everything I deserve, otherwise I won't feel satisfied & .550 \\
\hline 17.I love to become the focus of attention of others & .694 \\
\hline 18.I love watching myself in the mirror & .638 \\
\hline 19.I love watching a part of your body. & .671 \\
\hline 20.I have good taste in the aesthetic aspect & $\mathbf{. 1 9 3}$ \\
\hline
\end{tabular}

Table 2. Covert Narcissism Measurement

\begin{tabular}{|l|c|}
\hline Item & Load factor \\
\hline 21. I often feel useless. & .645 \\
\hline 22. the people and things around often makes me feel very satisfied. & .857 \\
\hline 23. I often feel. Everything is not true. & .688 \\
\hline 24. people often disappointed me. & .814 \\
\hline 25.I often feel that something is really too bad & .700 \\
\hline 26.I think we should find an appreciation of my people is not easy & .601 \\
\hline 27.I often think that someone has something he did not deserve & .685 \\
\hline 28.I envy other people's good luck. & $\mathbf{. 0 5 4}$ \\
\hline 29. I expect a lot from others &. $\mathbf{2 3 0}$ \\
\hline 30.if people do not pay attention to me, I will feel flat & .618 \\
\hline 31.unless I get everything I deserve, otherwise I won't feel satisfied & .550 \\
\hline 32.I love to become the focus of attention of others & .694 \\
\hline 33. I love watching myself in the mirror & .638 \\
\hline 34.I love watching a part of your body. & .671 \\
\hline 35.I have good taste in the aesthetic aspect. & $\mathbf{. 1 9 3}$ \\
\hline
\end{tabular}




\section{Table 3. Investment Professionals, Risk Propensity and Decision Satisfaction}

\begin{tabular}{|c|l|c|}
\hline variable & \multicolumn{1}{|c|}{ Item } & Load factor \\
\hline \multirow{5}{*}{$\begin{array}{c}\text { Investment } \\
\text { professionals }\end{array}$} & 36. I have experience in fund related products & .776 \\
\cline { 2 - 3 } & $\begin{array}{l}\text { 37. I have rich knowledge for financial products } \\
\text { 38. for some financial advice and recommendation of } \\
\text { the staff, I often don't understand(R) }\end{array}$ & .735 \\
\cline { 2 - 3 } & $\begin{array}{l}\text { 39.I know and understand their purchase of financial } \\
\text { products and services in all aspects }\end{array}$ & .645 \\
\hline \multirow{5}{*}{ risk propensity } & 40. for me, is worth the risk of investment & .557 \\
\cline { 2 - 3 } & 41.I can not accept the risk of investment (R) & .754 \\
\cline { 2 - 3 } decision & $\begin{array}{l}\text { 42.I am willing to accept the risk of failure } \\
\text { very frustrating (R) }\end{array}$ & .625 \\
\cline { 2 - 3 } satisfaction & 44. a good choice of many financial products & .732 \\
\cline { 2 - 3 } & 45. I think the selection process is very good & .694 \\
\cline { 2 - 3 } & $\begin{array}{l}\text { 46. if the next purchase, I hope to be able to choose this } \\
\text { again }\end{array}$ & $\begin{array}{l}\text { 47.I think the selection process of the financial product } \\
\text { purchase is very interesting }\end{array}$ \\
\cline { 2 - 3 } & $\begin{array}{l}\text { 48.my own experience in the selection process is very } \\
\text { satisfied }\end{array}$ & .743 \\
\hline
\end{tabular}

Table 4. The Latent Variable Correlation Coefficient

\begin{tabular}{|c|c|c|c|c|c|}
\hline & $\begin{array}{c}\text { overt } \\
\text { narcissism }\end{array}$ & $\begin{array}{c}\text { covert } \\
\text { narcissism }\end{array}$ & $\begin{array}{c}\text { Risk } \\
\text { appetite }\end{array}$ & $\begin{array}{c}\text { Investment } \\
\text { professionals }\end{array}$ & $\begin{array}{c}\text { decision } \\
\text { satisfaction }\end{array}$ \\
\hline $\begin{array}{c}\text { overt } \\
\text { narcissism }\end{array}$ & 1 & $.304^{* *}$ & $.406^{* *}$ & $.237^{* *}$ & $.310^{* *}$ \\
\hline $\begin{array}{c}\text { covert } \\
\text { narcissism }\end{array}$ & $.304^{* *}$ & 1 & .115 & $.215^{*}$ & .093 \\
\hline Risk appetite & $.406^{* *}$ & .115 & 1 & $.376^{* *}$ & $.542^{* *}$ \\
\hline $\begin{array}{c}\text { Investment } \\
\text { professionals }\end{array}$ & $.237^{* *}$ & $.215^{*}$ & $.376^{* *}$ & 1 & $.359^{* *}$ \\
\hline $\begin{array}{c}\text { decision } \\
\text { satisfaction }\end{array}$ & $.310^{* *}$ & .093 & $.542^{* *}$ & $.359^{* *}$ & 1 \\
\hline $\begin{array}{c}\text { mean value } \\
\text { standard } \\
\text { deviation }\end{array}$ & .3 .2952 & 2.1660 & 3.3740 & 2.3817 & 3.1740 \\
\hline AVE & 0.752 & 0.714 & 0.661 & 0.728 & .82663 \\
\hline CR & .812 & .902 & .744 & .831 & .877 \\
\hline
\end{tabular}

\subsection{Model Test}

By the analysis of table 5 , it can be seen that overt narcissism and risk propensity and decision-making satisfaction are related, and covert narcissism tendency and direction decision satisfaction are not related. Risk propensity plays a completely mediating role 
between overt narcissism and decision satisfaction. If the establishment of the $1,5,6,2,7$ is not established.

Table 5. Test the Mediating Effect of Risk Propensity

\begin{tabular}{|c|c|c|c|c|c|c|}
\hline \multirow[b]{2}{*}{$\begin{array}{l}\text { Independent } \\
\text { variables }\end{array}$} & \multicolumn{2}{|c|}{$\begin{array}{c}\text { Decision-making } \\
\text { satisfaction }\end{array}$} & \multicolumn{2}{|c|}{ Risk propensity } & \multicolumn{2}{|c|}{ Decision-making satisfaction } \\
\hline & $\begin{array}{c}\beta \\
\text { (Standardized } \\
\text { Coefficients) }\end{array}$ & $t$-value & $\begin{array}{c}\beta \text { (Standardized } \\
\text { Coefficients) }\end{array}$ & $t$-value & $\begin{array}{c}\beta \\
\text { (Standardized } \\
\text { Coefficients) } \\
\end{array}$ & $t$-value \\
\hline $\mathrm{C}$ & $1.848 * * *$ & 4.479 & -0.781 & -0.373 & $1.185 * * *$ & 3.127 \\
\hline overt nar. & $0.404 * * *$ & 3.515 & $2.355 * * *$ & 4.032 & 0.138 & 1.255 \\
\hline covert nar. & -0.002 & -0.015 & 0.628 & 0.883 & 0.006 & 0.045 \\
\hline risk pro. & & & & & $0.451 * * *$ & 6.153 \\
\hline Adjusted R2 & \multicolumn{2}{|c|}{0.482} & \multicolumn{2}{|c|}{0.429} & \multicolumn{2}{|c|}{$\frac{1}{0.687}$} \\
\hline$\triangle_{\mathrm{R} 2}$ & & & & & \multicolumn{2}{|c|}{0.551} \\
\hline$F$ & \multicolumn{2}{|c|}{$6.791 * * *$} & \multicolumn{2}{|c|}{$10.585 * * *$} & \multicolumn{2}{|c|}{$18.453 * * *$} \\
\hline$d f$ & \multicolumn{2}{|c|}{2} & \multicolumn{2}{|l|}{2} & \multicolumn{2}{|c|}{3} \\
\hline$N$ & \multicolumn{2}{|c|}{130} & \multicolumn{2}{|c|}{130} & \multicolumn{2}{|c|}{130} \\
\hline
\end{tabular}

By the analysis of table 6, we can see that investment professionals between overt narcissism and risk tendency play a positive regulatory role, but between covert narcissism and risk tendency effect was not significant. The higher the risk of overt narcissism tendency of customer investment professionals higher, Hypothesis 3 was established, Hypothesis 4 is not true.

\section{Table 6. Test the Moderating Effect of Professional Investment}

\begin{tabular}{|c|c|c|c|c|}
\hline \multirow[b]{2}{*}{ Independent variables } & \multicolumn{2}{|c|}{ Risk propensity } & \multicolumn{2}{|c|}{ Risk propensity } \\
\hline & $\begin{array}{c}\beta \text { (Standardized } \\
\text { Coefficients) }\end{array}$ & $t$-value & $\begin{array}{c}\beta \text { (Standardized } \\
\text { Coefficients) }\end{array}$ & $t$-value \\
\hline $\mathrm{C}$ & $1.179 * * *$ & 2.781 & -1.491 & -.696 \\
\hline overt narcissism & $.506^{* * *}$ & 4.283 & -.213 & -.312 \\
\hline covert narcissism & -.102 & -.709 & .236 & .288 \\
\hline $\begin{array}{c}\text { Investment } \\
\text { professional degrees }\end{array}$ & $.314 * * *$ & 3.816 & $2.830 * * *$ & 3.343 \\
\hline overt nar.* IPD & & & $.617 * *$ & 2.240 \\
\hline covert na. * IPD & & & -.313 & -1.014 \\
\hline Adjusted R2 & \multicolumn{2}{|c|}{0.633} & \multicolumn{2}{|c|}{0.857} \\
\hline$F$ & \multicolumn{2}{|c|}{$14.188^{* * *}$} & \multicolumn{2}{|c|}{$157.392 * * *$} \\
\hline$d f$ & \multicolumn{2}{|c|}{3} & \multicolumn{2}{|c|}{5} \\
\hline$N$ & \multicolumn{2}{|c|}{130} & \multicolumn{2}{|c|}{130} \\
\hline
\end{tabular}

\section{Conclusions}

The through the questionnaire survey method, to a bank in Zhengzhou, financial products, the customer as the research object, based on the theory of narcissism explore the narcissistic clients to invest in the financial products risk propensity and decision satisfaction, attempt to narcissistic customer investment psychological interpretation and research. Research results show that the customer's investment professional degree of the narcissistic personality influence risk propensity, the higher the degree of professional 
investment of overt narcissism customer risk tend to be more, the customer's investment professionals play their positive regulatory role. The customer has the obvious risk of overt narcissism tendency, but the risk of customer covert narcissism tendency is not obvious. May be due to overt narcissism customer due to the excessive self-esteem and self expansion characteristics determine that they have a higher self perceived good demand, willing to take risks to achieve higher goals, and don't be afraid to fail after the opinions of others; and covert narcissism customer due to susceptible quality characteristic is quite obvious, self esteem is obtained through the evaluation of others. It is difficult to bear the failure consequences and risk propensity is not significant. At the same time, the customer satisfaction is higher investment intermediary role in the risk of overt narcissism tendency, relationship between covert narcissism and investment customer satisfaction is not significant. This is because the narcissistic customer has more obvious tendency of risk that risk is worth, they can accept the risk brought huge gains May also cause huge losses to the fact. Therefore, based on the good psychological adjustment, they tend to less anxiety and be able to forgive investment failure, then would have a higher satisfaction of investment decision. Covert narcissism customers compared to overt narcissism customer risk propensity is weak, so the consequence of risk acceptance is low, so the investment decision of customer satisfaction is lower than overt narcissism.

The theoretical contributions of this paper are mainly two points: first, this study explored the intrinsic mechanism of narcissism influence financial products investment risk tendency, and the difference between overt and covert narcissism in the process. And found the positive regulation of professional variables - customer risk propensity to narcissism. Specific performance is significantly strong tendency of risk financial products in the investment process of narcissistic customers, and the risk tends to rise with the increasing of customer professional degree. Customer risk propensity of covert narcissism is not significant. Secondly, this paper will first narcissism, risk propensity and decision-making satisfaction of these three variables together, provide new ideas for the research on the field of narcissism. The results show that a high degree of overt narcissism customer's higher satisfaction on decision-making, customer covert narcissism is not significant. This paper enriches the related literature on narcissism.

In this paper, the practical significance is also very rich in the development of the financial industry increasingly mature today, by investing in financial products to increase the value of the people has become the preferred way. In the purchase of financial products, and a large part of the narcissistic personality, know the overt and covert narcissism risk propensity and decision satisfaction through this study, in favor of the bank's customer manager according to the different characteristics of customers recommend different products, with a suitable way to communicate with customers. In view of the characteristics of explicit customer high risk propensity and high investment satisfaction, product manager can design the project of high risk and high return financial products for overt narcissism customer. In addition, due to professional customers a positive moderating effect, customer manager for a high degree of professionalism of overt narcissism customer can also be bold recommendation of such financial products, and given the overt narcissism customer's decision to higher satisfaction and customer relationship is much easier.

In addition, limitations of the study, at first in the background of financial products, for other types of products, the conclusion of this paper is applicable also need further examination; secondly, the subjects are from Zhengzhou, a bank financial products to customers, future research could consider a number of units from the collected data. 


\section{References}

[1] D.Dunning, "Self-image motives and consumer behavior: How sacrosanct self-beliefs sway preferences in the marketplace", Journal of Consumer Psychology, Vol. 17, (2007), pp. 237-249.

[2] S.Y.Lee, A. Gregg and S.Park,"The person in the purchase: Narcissistic consumers prefer products that distinguish them",Journal of Personality and Social Psychology, Vol. 105, (2013), pp. 335-352.

[3] W.Campbell, B .Hoffman, S .Campbell and G .Marchisio, "Narcissism in organizational contexts",Human Resource Management Review, Vol. 21,(2011),pp.268-284.

[4] A.Luchner, J.Houston, C .Walker and M.Alex Houston, "Exploring the relationship between two forms of narcissism and competitiveness",Personality and Individual Differences, Vol. 51, (2011),pp.779-782

[5] P.Wink, "Two faces of narcissism", Journal of Personality and Social Psychology, Vol. 61, (1991),pp. 590-597.

[6] K.Dickinson and A.Pincus, "Interpersonal analysis of grandiose and vulnerable narcissism".Journal of Personality Disorders, Vol. 17, (2003),pp. 188-207.

[7] H.Hendin and J.Cheek, "Assessing hypersensitive narcissism: A reexamination of Murray's narcissism scale "Journal of Research in Personality, Vol. 31, (1997), pp. 588-599.

[8] P.Rose, "The happy and unhappy faces of narcissism". Personality and Individual Difference, Vol. 33, (2002), pp. 379-391.

[9] C.Lakey, "Frequent Card Playingand Pathologieal Gambling: The Utility of the Georgia Gambling Task and Iowa Gambling Task for Predicting Pathology”,Journal of Gambling Studies, Vol. 23, (2007), pp.285-297.

[10] C.Lakey, "eLillk between Narcissism and Gambling: The Mediating Role of Judgment and Decision making Biases",Journal of Behavioral decision Making, Vol. 21, (2008),pp.113-137.

[11] J.Foster, W .Campbell, "Individual Decision Narcissism: Inflated Self-views Across the Life's Pan and Around the World", Journal of Researching Personality, Vol. 37, (2003),pp.469-486.

[12] H.Minxue, Z. Xuechun, "Customer loyalty is more professional: An Empirical Study of the paradox of professional customer fund investors",Nankai business review, Vol. 17 ,(2014),pp.33-35.

[13] D.Jing, L.Yongfang, "Influence of decision maker and related variables on risk preference", Journal of psychology, Vol. 44,(2012),pp. 369-376.

[14] Z.Yong, "Overt narcissism and covert narcissism: the narcissistic personality", Journal of psychology. Vol. 28, (2005),pp.1259-1262.

[15] J. Pennings, B.Wansink, "A Note on Modeling Consumer Reactions to a Crisis: The Case of the Mad Cow Disease”, International Journal of Research in Marketing, Vol.19 (2002),pp.91-100.

[16] J. Fitzsimons, "Consumer Response to Stakeouts", Journal of Consumer Research, Vol. 27, (2000), pp.249-266.

[17] J.Nunnally, J. Bernstein, "Psychometric Theory", New York: McGraw-Hill, (1994).

[18] M. Johnson, M., Anderson, E., Fornell, C..Rational and Adaptive Performance Expectations in a Customer Satisfaction Frame- work. Journal of Consumer Research, Vol. 21,(1995),pp.695-707.

[19] C. Fornell, D.Larcker, "Evaluating Structural Models with Unobservable Variables and Measurement Error", Journal of Marketing Research, 1981, Vol. 18, (1981), pp.39-50. 